\title{
Fracture energy of hybrid polypropylene-steel fiber high strength concrete
}

\author{
H. S. J. Al Hazmi ${ }^{1}$, W. H. Al Hazmi ${ }^{2}$, M. A. Shubaili ${ }^{1}$ \\ \& H. E. M. Sallam ${ }^{1,3}$ \\ ${ }^{I}$ Civil Engineering Department, Jazan University, Saudi Arabia \\ ${ }^{2}$ Mechanical Engineering Department, Jazan University, Saudi Arabia \\ ${ }^{3}$ On sabbatical leave from Zagazig University, Egypt
}

\begin{abstract}
Fracture behavior of high strength concrete (HSC) with different types of short fiber (steel, polypropylene (PP), and steel $+\mathrm{pp}$ ) was investigated in the present work. The fracture behavior of edge-notched beam was determined in three-point bending condition. The crack length to depth ratio, a/d, was equal to $0.2,0.3,0.4$ and 0.5 . The fracture parameters were determined using linear elastic fracture mechanics (LEFM) and the Hillerborg model. The results in the present paper indicated that, adding short fibers to HSC improved its compressive strength in addition to the obvious enhancement in ductility. The mode of failure for various fiber reinforced concrete (FRC) types under compression was varied compared to that of plain concrete. All these cubes failed due to multiple tensile vertical cracks. In general, a small effect of short fibers in improving the indirect tensile strength and flexural strength of HSC. HSC with Steel and PP Hybrid Fiber (SPPFRC) showed superior compressive, tensile, and flexural strengths over the others FRCs. Fracture toughness based on LEFM $\left(\mathrm{K}_{\mathrm{IC}}\right)$ has a limited variation with increasing $\mathrm{a} / \mathrm{w}$ for HSC and all FRCs. Therefore, the mean value of $\mathrm{K}_{\mathrm{IC}}$ is calculated and trusted. The predicted values of undamaged defect based on LEFM are comparable to the maximum aggregate size. Therefore, the values of $\mathrm{K}_{\mathrm{IC}}$ calculated based on LEFM were reasonable.

Keywords: high strength concrete, hybrid fiber reinforced concrete, flexural toughness, linear and non-linear fracture mechanics, fracture energy.
\end{abstract}




\section{Introduction}

High strength concrete is a quasi-brittle material that has low tensile strength and low strain capacity. These drawbacks may be avoided by adding fibers [1]. Fiber reinforced concrete (FRC) is primarily made of hydraulic cements, fine and coarse aggregate and discontinuous discrete reinforcing fibers. Fibers suitable for reinforcing concrete have been produced from steel, plastic, glass, and natural materials in various shapes and sizes. The use of two or more fiber types in the same concrete mix is considered promising. The decision to mix two fibers may be based on the properties that they may individually provide or simply based on economics [2]. It appears possible, therefore, that by properly controlling fiber properties and combining them in appropriate proportions, one can actually tailor-make hybrid fiber composites for specifically designed applications.

In well-designed hybrid composites, there is positive interaction between the fibers and the resulting hybrid performance exceeds the sum of individual fiber performances. This phenomenon is often termed "synergy". Many fiber combinations may provide 'Synergy' with the most commonly recognized being [3]:

- Hybrids based on fiber constitutive response: One type of fiber is stronger, stiffer and provides reasonable first crack strength and ultimate strength, while the second type of fiber is relatively flexible and leads to improved toughness and strain capacity in the post-crack zone.

- Hybrids based on fiber dimensions: One type of fiber is smaller, so that it bridges micro-cracks and therefore controls their growth and delays coalescence. This leads to a higher tensile strength of the composite. The second fiber is larger and is intended to arrest the propagation of macrocracks and therefore results in a substantial improvement in the fracture toughness of the composite [4].

- Hybrids based on fiber function. One type of fiber is intended to improve the fresh and early age properties such as ease of production and plastic shrinkage, while the second fiber leads to improved mechanical properties.

\section{Experimental work}

The test specimens are divided into two groups:

- The first group was examined to find out the mechanical properties of different concretes. Included $100 \times 100 \times 100 \mathrm{~mm}$ cubes to measure their compressive strength, $100 \times 200 \mathrm{~mm}$ cylinders to measure their indirect tensile strength, and $100 \times 100 \times 500 \mathrm{~mm}$ unnotched prisms with loaded span of $400 \mathrm{~mm}$ to measure their flexural strength.

- The second group included $100 \times 100 \times 500 \mathrm{~mm}$ notched prisms with loaded span of $400 \mathrm{~mm}$ tested under three point bending 3PB to determine the fracture behavior under mode I. The notch length to beam depth ratio were $0.2,0.3,0.4$, and 0.5 . 


\subsection{Materials}

All test specimens were prepared using locally available materials. The cement, type I ordinary Portland cement, content for the control mix was $443 \mathrm{~kg} / \mathrm{m}^{3}$. Ordinary siliceous sand with fineness modulus of 2.7 , bulk density of $1700 \mathrm{~kg} / \mathrm{m}^{3}$ and specific gravity of 2.45 was used as fine aggregate. Coarse aggregate (dolomite) with a maximum nominal size of $14 \mathrm{~mm}$, bulk density of $1650 \mathrm{~kg} / \mathrm{m}^{3}$ and specific gravity of 2.56 was used. Light gray silica fume of specific surface area of $18 \mathrm{~m}^{2} / \mathrm{gm}$ was used. Silica fume content $10 \%$ (adding by weight of cement). The galvanized steel fiber used in this work is a new geometry of fiber where two plain fibers are crumpled around each other to form a filament fiber. This new shape of fiber achieves a good bond between the matrix and the fiber due to the development of the mechanical bond depending on the fiber geometry. The fiber length was $25 \mathrm{~mm}$ and the plain fiber cross sectional diameter was $0.5 \mathrm{~mm}$ so the aspect ratio was 50 , and the modulus of elasticity and the yield strength were $200 \mathrm{GPa}$ and $265 \mathrm{MPa}$, respectively. For Polypropylene fiber, the used type called "MC-Fiber", meets the requirements of ASTM C 1116 and C 1399. The fiber was $15 \mathrm{~mm}$ length and $0.0965 \mathrm{~mm} \pm 10 \%$ thickness. The modulus of elasticity and the ultimate tensile strength were $3700 \mathrm{MPa}$ and $600 \mathrm{MPa}$, respectively. Three fiber configurations shown in Table 1 were tested.

Table 1: $\quad$ Fiber configurations and abbreviations.

\begin{tabular}{cccc}
\hline Mix No. & Fiber Configuration & Abbreviation & Total $\mathbf{V}_{\mathbf{f}}$ \\
\hline 1 & - & PC or HSC & - \\
2 & $0.8 \%$ steel & SFRC & $0.8 \%$ \\
3 & $0.4 \%$ polypropylene & PPFRC & $0.4 \%$ \\
4 & $0.4 \%$ steel and $0.2 \%$ PP & SPPFRC & $0.6 \%$ \\
\hline
\end{tabular}

The mix proportion by weight for the control mix was 1: 1.34: 2.25: 0.29 (cement: sand: dolomite: water/[cementitious materials]). Due to the relatively low water content and the presence of silica fume and fibers, a superplasticizer was added to the mixing water to improve the workability and to keep the slump almost constant. The mixing sequences suggested by ACI Committee 544 were adopted in the present work.

\subsection{Test specimens and testing procedures}

The bending and fracture toughness test specimens were caste in wooden moulds while the compression and indirect tension specimens were caste in steel moulds. The moulds were coated by a thin layer of oil before casting. A steel plate of $0.5 \mathrm{~mm}$ thickness was used to create the notch at the tensile surface of fracture toughness test specimens. The age of tested specimens was 56 day. A universal hydraulic testing machine of $1000 \mathrm{kN}$ maximum capacity was used for testing all specimens. Dials indicator of a mechanical type having an accuracy of 
$0.002 \mathrm{~mm}$, and $0.01 \mathrm{~mm}$ were used to measure the crack mouth opening displacement, CMOD, and the mid-span vertical deflection for the flexural specimens.

\section{Results and discussion}

\subsection{Mechanical properties of PC and FRCs}

The effect of silica fume content and fiber volume fraction on compressive, indirect tensile and flexural strengths of hybrid FRC is recorded in Table 2. The compressive strength of $\mathrm{PC}$ was $53 \mathrm{MPa}$ which can be classified as high strength concrete. Reasonable development in compressive strength was observed due to the presence of fiber where the compressive strengths ranged from $55 \mathrm{MPa}$ and $62 \mathrm{MPa}$. SPPFRC showed the superior compressive strength (62 $\mathrm{MPa})$ over FRCs with single type of fiber.

Table 2: $\quad$ Mechanical properties of HSC and FRCs in MPa.

\begin{tabular}{|c|c|c|c|c|c|}
\cline { 2 - 6 } \multicolumn{1}{c|}{} & $\begin{array}{c}\text { Fiber } \\
\text { Type }\end{array}$ & $V_{f} \%$ & $\begin{array}{c}\text { Compressive } \\
\text { Strength, } f_{\mathrm{c}}\end{array}$ & $\begin{array}{c}\text { Tensile } \\
\text { Strength, } f_{\mathrm{t}}\end{array}$ & $\begin{array}{c}\text { Flexural } \\
\text { Strength, } f_{\mathrm{fl}}\end{array}$ \\
\hline HSC & - & - & 53 & 5.09 & 7.23 \\
\hline SFRC & Steel (S) & 0.80 & 55 & 5.19 & 6.20 \\
\hline PPFRC & PP & 0.40 & 58 & 5.41 & 8.1 \\
\hline SPPFRC & $\mathrm{S}+\mathrm{PP}$ & $\begin{array}{c}0.4 \mathrm{~S}+0.2 \\
\text { PP }\end{array}$ & 62 & 6.37 & 8.1 \\
\hline
\end{tabular}

As observed in compressive strength, SPPFRC experienced a superior tensile strength over the other types of FRCs. The splitting strength of HSC increased from 5.09 to $6.37 \mathrm{MPa}$ due to the addition of steel and PP hybrid fiber, i.e. $25 \%$ improvement. In general, the little effect of fiber to improve the tensile strength may be due to the random orientation of the fibers and their distribution all over the matrix in addition to the high percentage of coarse aggregate which decreases the efficiency of fibers to bridge the splitting crack. The ratios of the flexural to tensile strength for PC and FRCs ranged from 1.2 to 1.5. This may be attributed to the tensile stress on the fractured surface of indirect tensile specimen is almost constant, while a gradient distribution of tensile stress across the section of bending specimen made the failure occurred successively, i.e. no sudden failure as occurred in indirect tensile test. Figure 1 is evidence for the previous argument, random orientation of the short fibers and their distribution all over the matrix in addition to high percentage of coarse aggregate are the main factors to minimize the benefit of the presence of fiber. The amount of internal voids for each FRC and PC can be seen from this figure. It is clear that, the highest amount of voids was found in SFRC due to the high fiber stiffness. High fiber stiffness may also result in the bad distribution of coarse aggregate. These observations may illustrate why the flexural strength of SFRC is lower than that of PC. On the other hand, Ibrahim et al. [5] found that the addition of plain steel, 
or polypropylene, or hybrid fiber to the plain concrete with 1:1 ratio of coarse to fine aggregate increased the compressive, flexural, and tensile strengths of that plain concrete with reasonable ratios.
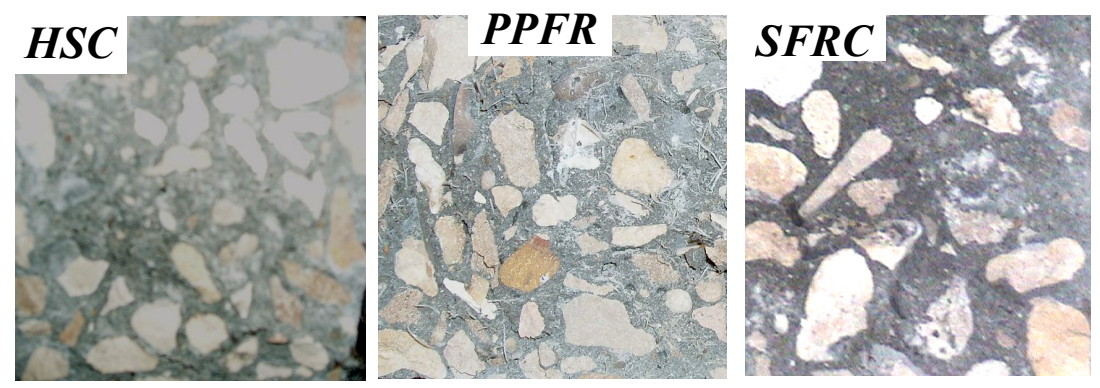

Figure 1: $\quad$ The fractured surface of flexural specimens for PC and FRCs.

To illustrate the effect of fiber in delaying the crack growth of flexural cracks, from the energy point of view, the ratio of the total strain energy absorbed by the material (toughness), up to failure, to the strain energy absorbed up to the ultimate load $(\approx$ resilience) was calculated. Table 3 shows the toughness-toresilience $(T / R)$ ratios of different materials, if $T / R=1$ this means unstable crack growth. Although SFRC has the lowest value of flexural strength because it contains many internal voids and bad coarse aggregate distribution, crumbled steel fibers showed the most efficient crack retardation due to their geometry, which improved the bond between them and cement paste. SFRC showed a superior flexural toughness over the others FRCs. On the other hand, Sorelli et al. [6] used a hybrid combination of short and long steel fibers to optimize structural behavior of concrete slabs on ground. They concluded that, "higher energy dissipation at small crack openings for hybrid systems of fibers (cocktail of fibers having different lengths) and encourage further research on this topic". Functionally graded material is the best technique to improve the efficiency of adding short fibers to PC. Recently, Ibrahim et al. [5] studied the effect of partially distributed fiber over depth in fiber reinforced concrete. They found that, the partial depth of $75 \%$ is more efficient than that of full depth FRC.

Table 3: $\quad \mathrm{T} / \mathrm{R}$ ratio of $\mathrm{PC}$ and FRCs.

\begin{tabular}{|c|c|c|c|}
\cline { 2 - 4 } \multicolumn{1}{c|}{} & Resilience, N.m & Toughness, N.m & T/R \\
\hline PC & 6.18 & 6.18 & 1 \\
\hline SFRC & 6.45 & 20.88 & 3.24 \\
\hline PPFRC & 8.1 & 12.64 & 1.56 \\
\hline SPPFRC & 7.42 & 15.35 & 2.1 \\
\hline
\end{tabular}

\subsection{Fracture toughness of PC and FRCs}

Nelson et al. [7] divided the $\sigma$-CMOD curve to five zones, three in the ascending part and two in the descending part. Zone I is characterized by linear-elastic 
behavior. Zone II contains the nonlinear deformation of the composite resulting from microcrack formation. In zone III, the localized failure crack has formed and is growing in a stable manner. Zone IV contains the unstable growth of the localized failure crack. Finally, in zone V, the failure crack has propagated across the entire specimen's depth, and only the bridging fibers carry load. On the other hand, Sallam [8] found that, the size of zone II and zone III is small and it can be ignored for simplicity. Therefore, he suggested that [8] trilinear $\sigma$ CMOD curve to explain the deformation in FRC. The validity of this explanation is based on the size of zones II and III which may depend on the fiber volume fraction, the bond strength between fiber and concrete, and the fiber geometry.

The present experimental results showed that, trilinear $\mathrm{P}-\delta$ curve is also valid to present the present results. The suggested mean curves of those data were plotted in Fig. 1. It is worth to note that, due to the process of pre-notch casting there are no fibers bridge on the two pre-notch surfaces, however, the surfaces of generated crack from the notch root are connected to each other through fibers. Thus, there are two main differences between the behavior of a crack emanating from pre-notch and that of successively growing crack, namely, fiber bridging and stress distribution around crack-tip or notch-root. This means that, if the strain energy release rate, $G$, is calculated based on subtracting the area of the two $\mathrm{P}-\delta$ curves up to the maximum load $(\mathrm{P}-\delta$ curve of $\mathrm{a} / \mathrm{w}=0.2-\mathrm{P}-\delta$ curve of

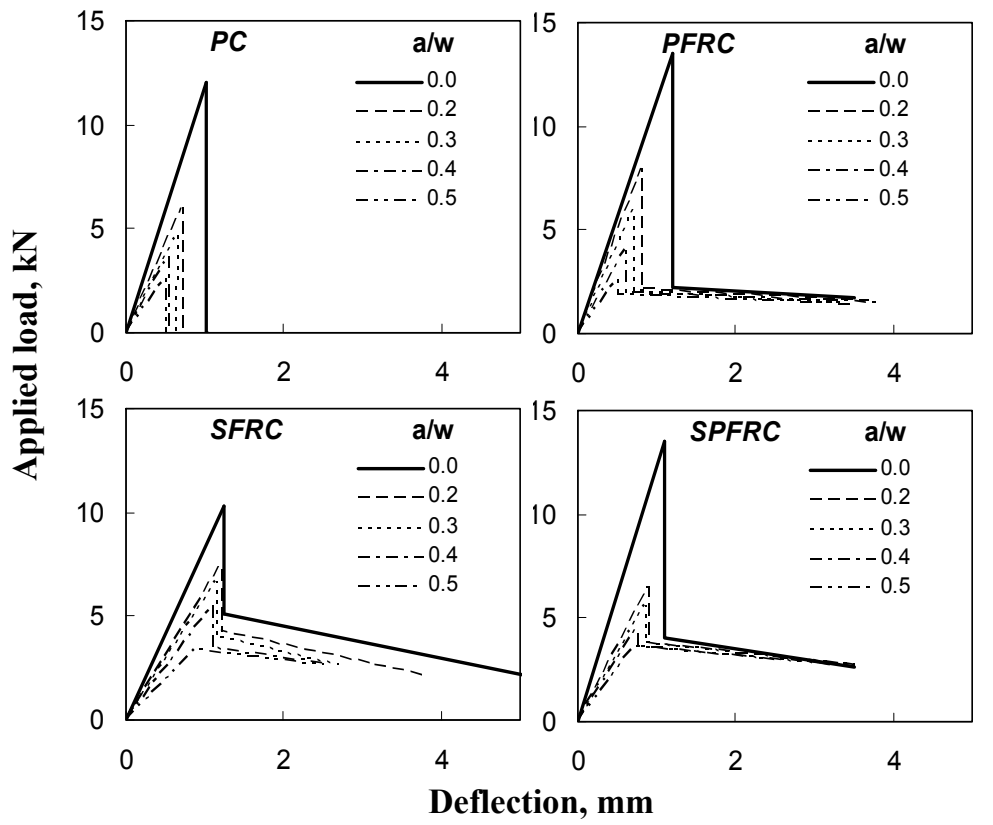

Figure 2: $\quad \mathrm{P}-\delta$ curve of PC and FRCs beams with different pre-notch depths. 
$\mathrm{a} / \mathrm{w}=0.3$ ) divided by the difference in the cracks areas, the results will suffer from the above two differences in addition to the large increment of the crack = 0.1 of the beam depth.

To determine the accuracy of this approach, Table 4 contains the values of strain energy release rate of PC and FRCs for different notch depths. As known, the fracture toughness can be expressed by $G, \mathrm{~K}_{\mathrm{IC}}=\sqrt{ }(G \mathrm{E})$. The values of $G$ calculated from smooth specimens and notched specimens with $\mathrm{a} / \mathrm{w}=0.2 \operatorname{did}$ not match with the values obtained from other specimens, as shown in the Table 4. It is clear that, there is a wide discrepancy between the values of $G$ in each material. Most of FRCs has steady state of crack propagation which appears in the descending part of the P- $\delta$ curve. Therefore, $G$ can be calculated based on the descending part only, i.e. depending on a real situation of propagating crack. The crack emanating from the notch root jumped up to 0.6 the depth regardless the initial notch depth. Thus, the $G$ was calculated as the mean value of the area of the different descending parts divided by the un-cracked area $(1-0.6) \times \mathrm{w} \times \mathrm{b}$. It is clear that, the value of $G$ calculated by this method is higher than those calculated based on the ascending part. This may be attributed to considering the effect of fiber bridging in descending part.

Table 4: $\quad$ Strain energy release rate of PC and FRCs.

\begin{tabular}{|c|c|c|c|c|c|c|}
\hline \multicolumn{2}{|r|}{$\mathrm{a} / \mathrm{w}$} & $0-0.2$ & $0.2-0.3$ & $0.3-0.4$ & $0.4-0.5$ & Descending \\
\hline \multirow{4}{*}{$\frac{\Xi}{\Xi}$} & $\mathrm{PC}$ & 2.04 & 0.61 & 0.5 & 0.34 & - \\
\hline & SFRC & 0.98 & 0.68 & 0.80 & 1.45 & 1.87 \\
\hline & PPFRC & 2.45 & 1.1 & 0.9 & 0.55 & 1.27 \\
\hline & SPPFRC & 2.25 & 0.55 & 0.69 & 0.41 & 2.21 \\
\hline
\end{tabular}

Table 5 shows the values of $\mathrm{K}_{\mathrm{IC}}$ based on LEFM. It is clear that, $\mathrm{K}_{\mathrm{IC}}$ has a small decrement with increasing $\mathrm{a} / \mathrm{w}$ for PC and all FRCs except SPPFRC, where, it showed an opposite trend. In general, the variation of the values of $\mathrm{K}_{\mathrm{IC}}$ vs. a/w is limited. Therefore, the mean value of $\mathrm{K}_{\mathrm{IC}}$ is calculated and trusted. According to ACI code, $\mathrm{E}=4700 \sqrt{ }\left(f_{\mathrm{c}}^{\prime}\right) \mathrm{MPa}$, where $f_{\mathrm{c}}^{\prime}=$ cylinder compressive strength, $\mathrm{E} \approx 31 \mathrm{GPa}$. Then based on Hillerborg concept [9], $\mathrm{K}_{\mathrm{IC}}=7.60,6.30$, and $8.10 \mathrm{MPa} \sqrt{\mathrm{m}}$ for SFRC, PPFRC, and SPPFRC respectively. As expected, there is a difference between the calculated value of $\mathrm{K}_{\mathrm{IC}}$ by LEFM and the Hillerborg concept (energy concept). The largest size of undamaged internal defect $\left(d_{\max }\right)$ in the smooth specimen, is equivalent to the characteristic length (L)

Table 5: $\quad$ Fracture toughness of PC and FRCs based on LEFM.

\begin{tabular}{|c|c|c|c|c|c|c|}
\hline \multicolumn{2}{|r|}{$\mathrm{a} / \mathrm{w}$} & 0.2 & 0.3 & 0.4 & 0.5 & Mean \\
\hline \multirow{4}{*}{ 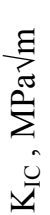 } & $\mathrm{PC}$ & 0.89 & 0.89 & 0.88 & 0.88 & 0.89 \\
\hline & SFRC & 1.11 & 1.06 & 0.95 & 0.94 & 1.02 \\
\hline & PPFRC & 1.189 & 1.15 & 1.00 & 0.88 & 1.06 \\
\hline & SPPFRC & 0.97 & 1.08 & 1.13 & 1.23 & 1.1 \\
\hline
\end{tabular}


proposed by Susmel and Taylor [10], i.e. after that size the strength of smooth specimen decreases with increasing the size of this defect. This depth can be predicted using the equation of SIF by this form:

$$
d_{\max }=\left(\mathrm{K}_{\mathrm{IC}} / 1.12 f_{\mathrm{fl}}\right)^{2} / \pi
$$

It is clear that, the predicted values of undamaged defect based on LEFM are comparable to the maximum aggregate size. Therefore, the values of $\mathrm{K}_{\mathrm{IC}}$ calculated based on LEFM were reasonable. However, the values of $\mathrm{K}_{\mathrm{IC}}$ calculated based on Hillerborg were illogic as shown in Table 6. Therefore, the calculated energy release rate either by ascending or by descending curve is not accurate. Furthermore, $\mathrm{Wu}$ et al. [11] proposed an analytical model based on Lagrange Multiplier Method to predict effective fracture toughness, the maximum load, and the critical effective crack length by knowing the elastic modulus and flexural strength. They found that, fracture parameters are not sensitive to the shape of the softening (descending) curve. This means that, they are in agreement with the present analysis regarding Hillerborg model. It is worth to mention that, $\mathrm{Oh}$ et al. [12] found the relation between CMOD and central deflection of FRC beam to be very much similar for different fiber volume fractions. Therefore, this relation of CMOD versus central displacement may be regarded as a material property for structural synthetic fiber reinforced concrete beam.

Table 6: $\quad$ Prediction of $d_{\max }$ based on LEFM and Hillerborg.

\begin{tabular}{|c|c|c|c|c|}
\cline { 2 - 5 } \multicolumn{1}{c|}{} & \multicolumn{2}{c|}{ LEFM } & \multicolumn{2}{c|}{ Hillerborg } \\
\cline { 2 - 5 } \multicolumn{1}{c|}{} & $d_{\max }, \mathrm{mm}$ & $d_{\max } / \mathrm{MAS}$ & $d_{\max }, \mathrm{mm}$ & $d_{\max } / \mathrm{MAS}$ \\
\hline PC & 3.9 & 0.28 & - & - \\
\hline SFRC & 8.2 & 0.59 & 382.19 & 27.3 \\
\hline PPFRC & 5.5 & 0.39 & 152.27 & 10.88 \\
\hline SPPFRC & 3.6 & 0.26 & 254.18 & 18.16 \\
\hline
\end{tabular}

\section{Conclusions}

From the experimental results obtained in this study, the following conclusions can be drawn:

1. High strength concrete with steel and polypropylene hybrid fiber (SPPFRC) showed the superior compressive strength, tensile strength, and flexural toughness over PC and all FRCs with single type of fiber.

2. HSC and all FRCs show linear behavior of P- $\delta$ curve up to the ultimate load with no visible cracks. There are two patterns of the descending part of $\mathrm{P}-\delta$ curve. In the case of PC the specimen failed suddenly combined with almost vertical descending part, i.e. unstable crack growth. In the case of FRCs, the crack jump from zero length to about $60 \%$ of specimen depth at the same deflection with considerable reduction in the applied 
load ranged from $50 \%$ to $70 \%$. Then the load decreases gradually with increasing in deflection.

3. Fracture toughness based on LEFM $\left(K_{I C}\right)$ has a limited variation with increasing a/w for PC and all FRCs. Therefore, the mean value of $K_{I C}$ is calculated and trusted.

4. The predicted values of the maximum size of undamaged defect based on LEFM are comparable to the maximum aggregate size. Therefore, the values of $K_{I C}$ calculated based on LEFM were reasonable. However, the values of $K_{I C}$ calculated based on Hilleborg were illogic.

\section{References}

[1] Lee, M. K. and Barr, B. I. G., Strength and fracture properties of industrially prepared steel fibre reinforced concrete, Cement and Concrete Composites, 25(3), pp.321-332, 2003.

[2] Walton, P.L., and Majumdar, A.J., Cement-based composites with mixtures of different types of fiber, Composites, 6(5), pp.209-216, 1975.

[3] Xu, G., Magnani, S., and Hannant, D.J., "Durability of hybrid polypropylene- glass fiber cement corrugated sheets", Cement and Concrete Composites, 20(1), pp.79-84, 1998.

[4] Banthia, N. and Sappakittipakorn, M., Toughness enhancement in steel fiber reinforced concrete through fiber hybridization, Cement and Concrete Research, 37(9), pp.1366-1372, 2007.

[5] Ibrahim K.I.M., Sallam H.E.M., Ibrahim F.K., Sharobim K.G. and Khalil M.S., Flexural behavior of partial depth of hybrid fiber reinforced concrete beams, Eleventh Int. Colloquium on Struct. and Geotec. Engng., 11th ICSGE, On CD-Rom, Paper code: E05RC 18, Ain Shams Univ., Cairo, Egypt, 17-19 May, 2005.

[6] Sorelli, L. G., Meda, A., and Plizzari, G. A., Steel Fiber Concrete Slabs on Ground: A Structural Matter, ACI Structural Journal, 103(4), pp.551-558, 2006.

[7] Nelson, P. K., Li, V., and Kamada, T., Fracture Toughness of Microfiber Reinforced Cement Composites, Journal of Materials in Civil Engineering, 14(4), pp.384-391, 2002.

[8] Sallam, H.E.M., Fracture Energy of Fiber Reinforced Concrete, Al-Azhar University Engineering Journal, 6(5), pp.555-563, 2003.

[9] Hillerborg A., Analysis of fracture by means of the fictitious crack model, particularly for fiber reinforced concrete, The International Journal of Cement Composites, 2(3), pp.177-186, 1980.

[10] Susmel, L. and Taylor, D., A Novel Formulation of The Theory of Critical Distances to Estimate Lifetime of Notched Components in The MediumCycle Fatigue Regime, Fatigue and Fracture of Engineering Materials and Structures, 30(7), pp.567-581, 2007. 
[11] Wu, Z., Yang, S., Hu, X., and Zheng, J., An Analytical Model to Predict the Effective Fracture Toughness of Concrete for Three-point Bending Notched Beams, Engineering Fracture Mechanics, 73(15), pp. 2166-2191, 2006.

[12] Oh, B. H., Kim, J. C., and Choi, Y. C., Fracture behavior of concrete members reinforced with structural synthetic fibers, Engineering Fracture Mechanics, 74(1-2), pp.243-257, 2007. 